\title{
AMCP Partnership Forum: Designing Benefits and Payment Models for Innovative High-Investment Medications
}

\section{SUMMARY}

High-investment medications, such as gene therapy and innovative specialty medications, offer breakthrough treatments that can greatly improve outcomes to patients with serious health conditions. However, many of these therapies are associated with significant costs that create barriers to patient access and affordability. Such innovative treatments have higher short-term costs, compared with current standards of care, but are anticipated to deliver substantial benefits that may persist over a long period of time, such as reduced mortality, improved health and quality of life, reduced health care costs, improved productivity, and reduced disability.

The effect of these changes on patterns of treatment costs can vary significantly over time across payers. For example, the initial payer who covers a one-time treatment invests more resources than a payer that covers a cured enrollee later in life. Thus, high-investment medications raise questions about how costs are managed and distributed across systems and payers, including patients.

As more high-investment medications are approved, some stakeholders are concerned that the current system for managing these medications will become unsustainable. It is clear that innovative and novel strategies are needed to support patient access to these new treatments, while addressing concerns about sustainability of the health care system in the United States.

To explore new benefit designs and payment models for high-investment medications, the Academy of Managed Care Pharmacy convened a stakeholder forum on July 24-25, 2018. Health care leaders representing academia, health plans, integrated delivery systems, pharmacy benefit managers, employers, national professional associations, the federal government, and biopharmaceutical companies participated in the forum. During the forum, participants engaged in thoughtful discussions regarding challenges and opportunities associated with innovative strategies for providing coverage for high-investment medications. The goals of the forum were as follows: (a) gain insights based on participants' unique perspectives on how the managed care ecosystem views high-investment medications for chronic versus curative diseases; (b) develop new solutions for benefit designs and overall value assessment for high-investment medications; (c) identify nontraditional contracting methods and reimbursement models to address high-investment medication challenges; (d) learn how to work with the Centers for Medicare \& Medicaid Services and state Medicaid officials to garner support and coverage of these medications; (e) determine whether any legal or regulatory barriers exist for new types of benefit designs and look for opportunities to address those barriers; and (f) develop best case solutions of high-investment medications in order to overcome potential challenges and achieve sustainable appropriate use.

J Manag Care Spec Pharm. 2019;25(2):156-62

Copyright $\odot 2019$, Academy of Managed Care Pharmacy. All rights reserved.
A $\mathrm{s}$ a result of a robust drug development pipeline, clinically transformative therapies have begun to enter the market, creating a sense of urgency among stakeholders to address the challenges of managing these therapies using current payment models, while also ensuring sustainability for payers, providing patient access, and supporting ongoing innovation.

Although they are associated with a high cost, new treatments may reduce the overall total cost of care and shift costs from one benefit type (e.g., medical) to another (e.g., pharmacy; Figure 1), with the specific effects depending on specific disease and therapy characteristics. Modeling the effects in a range of sample disease-therapy combinations and affected payers (Table 1) suggests that a combination of approaches will be needed to address the needs of various market dynamics and stakeholders. ${ }^{1}$

A recent survey of 21 national and regional managed care organizations representing 123 million commercial, Medicare Advantage, and managed Medicaid covered lives revealed that the financial risks and effects of high-investment medications are important concerns for payers and that they are interested in alternative payment models, given the right circumstances. Payers expect that they will likely use a combination of traditional and alternative payment models to manage high-investment medications. Key findings from the survey were presented during the AMCP Partnership Forum titled "Designing Benefits and Payment Models for Innovative High-Investment Medications" and are shown in Table $2 .^{2}$

To explore new benefit designs and payment models for high-investment medications, the Academy of Managed Care Pharmacy (AMCP) convened this stakeholder forum on July 24-25, 2018, with participation from health care leaders representing academia, health plans, integrated delivery systems, pharmacy benefit managers, employers, national professional associations, the federal government, and biopharmaceutical companies. During the forum, participants engaged in thoughtful discussions regarding challenges and opportunities associated with innovative strategies for providing coverage for high-investment medications.

Innovative Benefit Designs for High-Investment Medications Forum participants discussed the challenges associated with the development and implementation of innovative payment strategies including the needs of various stakeholders, the fragmented payer landscape, market constraints, evolving standards of care, strategies for aligning innovative payment models with benefit lifecycles, budget cycle timelines, legal and 


\section{MEDICATION COSTS}

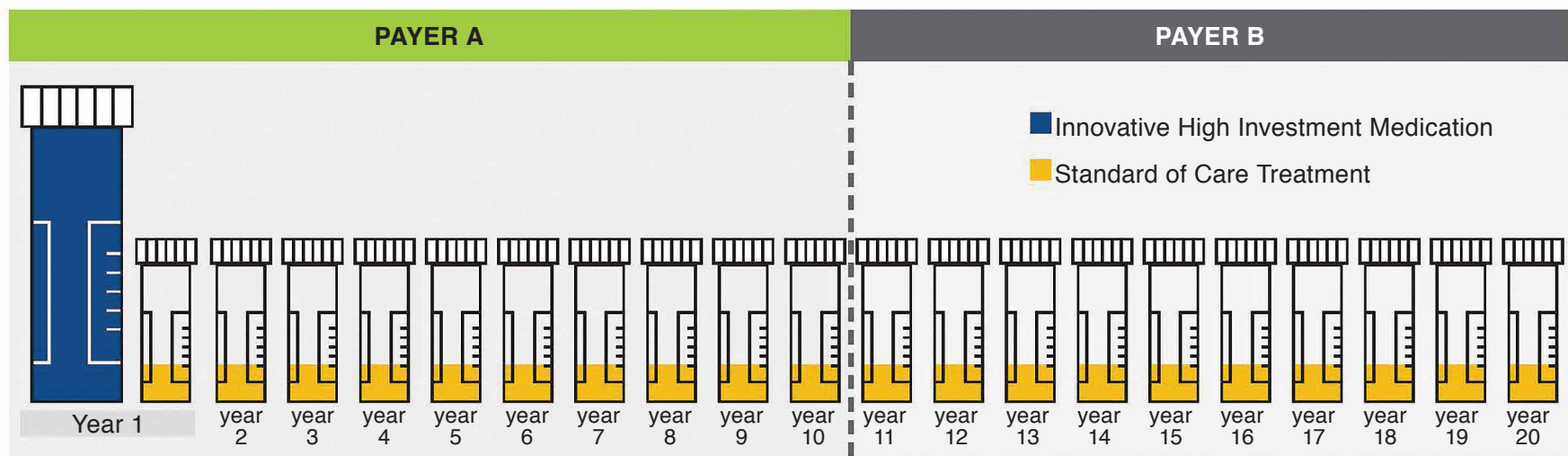

Large one-time treatment cost replaces continuous treatment under current

Years from First Treatment (1-20 years) standard of care

OTHER HEALTH CARE COSTS

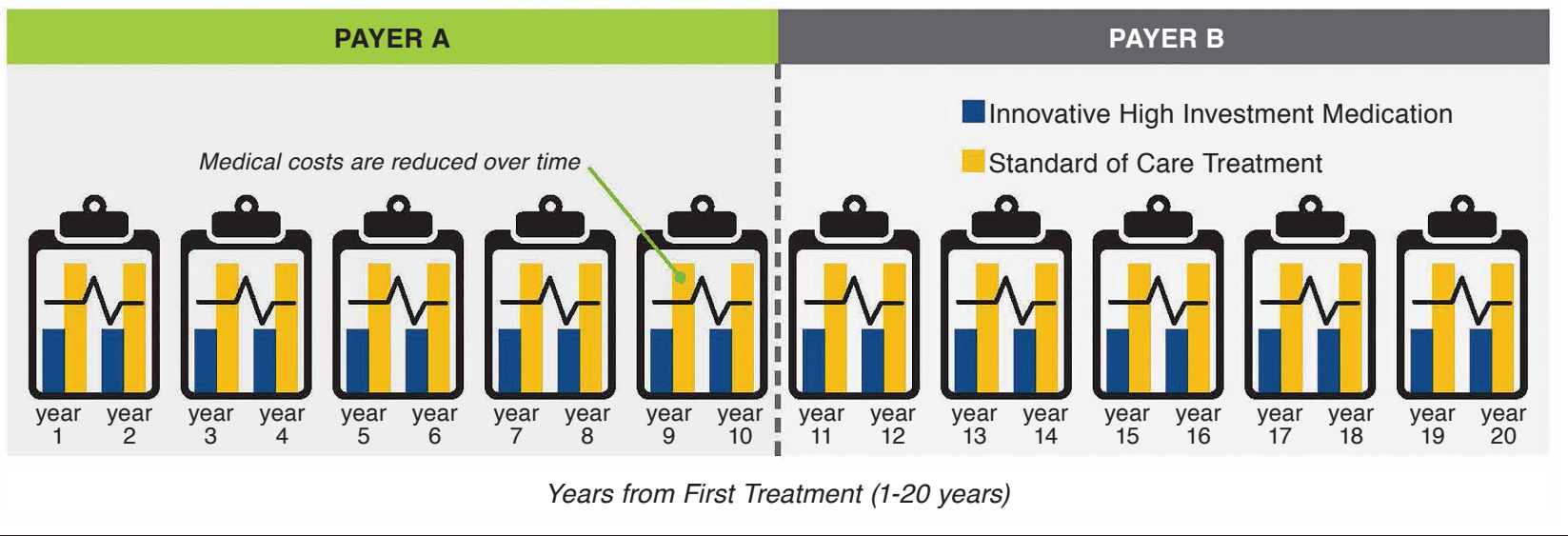

regulatory barriers, and the need for long-term, real-world data for assessing outcomes.

While all health care payers will be affected by high-investment medications, payers' underlying organizational characteristics will affect their risk management needs. For example, state Medicaid programs may face significant pressures because of the need to balance annual state budgets. Large payers, such as those with a national presence, may be better positioned to absorb variations in costs, while smaller ones, such as regional plans, may need to manage risk and variability by amortizing costs or participating in reinsurance pools.

Participants observed that therapies with curative or durable effects will likely require benefit designs that differ from those offered for chronic therapies because the entire cost of these treatments occurs as a 1-time event. However, it is important to note that fast-track, breakthrough therapies; personalized medicine interventions; and other innovative treatments are often approved by the U.S. Food and Drug Administration (FDA) based on small, short-term clinical trials. Real-world assessments of the efficacy and durability of the treatment, as well as safety, are needed to assess long-term outcomes and to inform benefit designs. Therefore, payers may opt to address new curative or durable treatments with contracts that link payments to performance.

Financing options that amortize costs may be a desirable approach but challenges remain. Such options may base payments on long-term effects by using outcomes-based contracts that align payment with performance measures over time. However, implementing this approach is a challenge in the current system because patients often change insurance plans, and the downstream plan may have different coverage criteria or contracts in place for a treatment. Nevertheless, downstream 


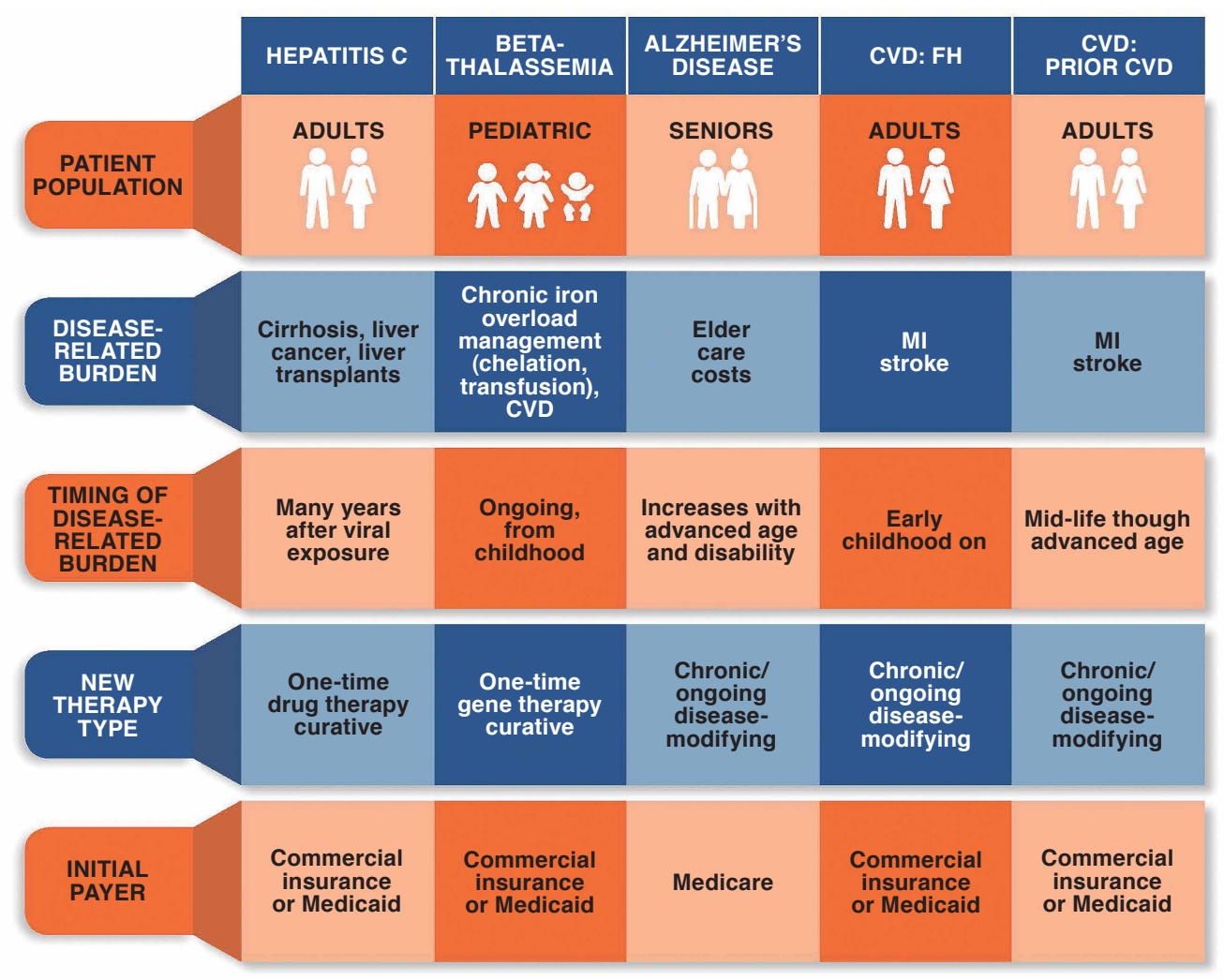

Source: Cutler D, Ciarametaro M, Long $G$, et al. Insurance switching and mismatch between the costs and benefits of new technologies. ${ }^{1}$

$C V D=$ cardiovascular disease; $F H=$ familial hypercholesterolemia; $M I=$ myocardial infarction

payers (e.g., commercial payers or Medicare) may reap substantial benefits from the investment made by the initial payer.

\section{Insights Regarding Selected Payment Strategies}

Several innovative payment strategies for high-investment medications have been proposed or are already utilized. Forum participants considered 4 different payment strategies: annuity payments, reinsurance markets, performance-based contracts, and milestone-based contracts. Annuity payments and reinsurance markets provide financial mechanisms for managing upfront financial risk, while performance-based contracts and milestone-based contracts base payment on outcomes. It is important to note that there are other possible approaches; forum participants selected these 4 options for discussion based on their areas of expertise. In addition, participants differed in their views of the potential benefits or disadvantages of the approaches discussed. Further evaluation of these and other approaches is warranted.

Annuity Payments. Annuities allow payers to make installment payments over an extended period. Participants considered annuity payments to be a viable financing model for short-term high-investment curative or durable therapies. Although they are not inherently tied to outcomes, participants did discuss the concept of linking annuity payments to outcomes, which would essentially convert the annuity to an extended outcomes-based contract. ${ }^{3}$

The idea of patient annuity payments was also discussed but was considered financially impractical for most patients. Therefore, they were not considered a viable systematic solution to manage high-investment medications.

Annuity payments amortize costs but do not address the price of treatment unless they are combined with other contracting strategies. Therefore, annuities might be most suited to treatments where a large initial treatment population is expected. On the other hand, if the number of patients requiring a treatment is consistent from year to year, any financing costs could affect the overall costs of care.

In general, annuity contracts must consider various scenarios, such as a patient who switches plans or dies during the term of annuity payments. A relatively short repayment time frame (e.g., 3-4 years) may be preferred to manage these risks. ${ }^{2}$ 


\section{TABLE 2 Payer Survey: Key Findings Regarding} Gene Therapy

KEY FINDING 1: Financial risk and impact of gene therapies is an important concern for payers

KEY FINDING 2: Payers would consider alternative payment models to manage plan risk under the right set of circumstances

KEY FINDING 3: Payers expect to use a combination of new and existing approaches to manage the financial risk of gene therapy

KEY FINDING 4: Given uncertainty about magnitude and duration of clinical effects, payers likely will require performance guarantees with alternative payment approaches

KEY FINDING 5: Greatest patient access challenges may be encountered at smaller employer plans and managed Medicaid plans

KEY FINDING 6: Payers' preferred approaches may not be entirely effective in addressing their concern

KEY FINDING 7: Many payers were uncomfortable with "patient portability" proposals

Source: Ciarametaro $M$, Long $G$, Johnson $M$, et al. Are payers ready to address the financial challenges associated with gene therapy? ${ }^{2}$

Reinsurance Markets. In this model, payers are insured by a third party to protect against high-cost claims. ${ }^{3}$ Because they pool risk, reinsurance products are generally most useful for smaller payers and self-insured employers who have a need to share risks and costs, whereas larger plans are more able to predict the size of their risk pool and factor costs into their plan premiums. Participants noted that reinsurance markets could also be developed for specific types of products, such as gene therapies, and could cover the entire episode of care or annual per patient costs, rather than just the product.

Participants concluded that reinsurance markets are only a short-term solution to address financial risk for smaller entities. Long-term reinsurance premiums are likely to rise as more highinvestment medications enter the market. Research is needed to better understand the potential effects of these models.

Performance-Based Payments. Performance-based payments, like milestone-based contracts, are most appropriate for treatments associated with clinical uncertainty. In this type of model, payments are made based on the achievement of predetermined outcomes. ${ }^{3}$ To be successful, outcomes must be clinically appropriate, relevant, and measurable, and the patient population must be clearly defined with specific inclusion and exclusion criteria for coverage decisions.

Outcomes are often more easily defined for therapies with durable effect, but these types of contracts can also be used for chronic therapies. When used for chronic therapies, it is important that they include appropriate care coordination and interventions over time. In addition, it is necessary to develop an infrastructure for capturing and analyzing real-world evidence regarding the performance.
Several regulatory issues were raised by different participants as barriers to the use of these contracts, such as Medicaid best price and other price-reporting constraints, the federal Anti-Kickback Statute, the potential for contracting for off-label indications, and potential patient information confidentiality risks that arise from the Health Insurance Portability and Accountability Act.

Milestone-Based Contracts. Milestone-based contracts are similar to performance-based contracts and have similar issues regarding regulation, needs for well-defined and measurable milestones, and the need for access to real-world data. The key difference is that payment is based on achievement of specific events such as initial therapy administration and therapeutic response, rather than being based on outcomes over time. Milestones could also be based on process measures.

\section{Considerations for Contracting Approaches}

\section{to Support Access}

Participants considered how various factors could influence new benefit designs, including marketplace factors, patient engagement activities, strategies for defining value, patient selection, and legal and regulatory challenges.

\section{Marketplace Factors}

Payers may have challenges assessing risk over time and integrating new financing models with existing benefits. The application of new models to different types of benefits, including medical benefits, pharmacy benefits, and high-deductible plans must also be considered.

The effect of rebates on pricing structures was cited as an important factor to consider when implementing new payment and coverage schemes. Participants stressed that innovative contract models are distinct from rebates and that the cost savings to payers associated with rebates on current therapies must be taken into consideration in designing new models.

Some participants cautioned that coverage plans that are generous compared with local competitors may run the risk of adverse selection by attracting high-risk or high-cost patients, putting them at a competitive disadvantage. Various ideas were suggested to address this situation, including enforceable "guardrails" to set required parameters for coverage consistently in a regional market. However, participants did not favor government mandates (e.g., state-level covered benefit requirements), but they supported the opportunity for defined and limited collaboration among stakeholders for elements, such as required coverage definitions, performance contract outcome measurement, and patient tracking over time.

Some stakeholders recognized that current laws and regulations pose real or perceived barriers to implementing this recommendation and that creative thinking is required to develop appropriate and concrete proposals for new models. State laws and regulations are also constantly evolving, and relevant changes should be considered to support new model designs. 


\section{Patient Engagement Activities}

Patient engagement and partnership is particularly important for chronic therapies to ensure that patients are adherent and persistent with the high-investment therapy and any ancillary services, such as follow-up appointments and tests to assess the effect of the treatment.

Clarity, transparency, and predictability for costs and coverage are important principles for guiding interactions with patients and ensuring that patients are aware of any cost-sharing responsibilities. Providing accurate and comprehensive cost information to patients is crucial and ideally should occur at the point of service or time of decision making.

Patient health literacy gaps must also be addressed to support patient understanding of financial obligations. Participants noted that care coordination and coaching will be important to assist patients with understanding plan designs and addressing cost barriers, for example, by assisting them with enrolling in appropriate patient assistance programs.

\section{Defining Value for High-Investment Medications}

The paradigm for value assessments of high-investment medications should employ a comprehensive approach considering a variety of factors that include survival, quality of life, effectiveness, safety, the patient's perspective, and comprehensive medical and prescription costs. Novel value assessment methodologies, such as multiple criteria decision analysis, may need to be applied for high-investment medications to comprehensively capture their value. Ideally, the value of the standard of care has already been identified, so that comparisons with the value of high-investment medications can take place.

Real-world evidence was seen as particularly useful for assessing the durability of treatment interventions and was recommended by some as a component of innovative contract models (e.g., coverage with evidence generation). However, the infrastructure to capture and assess real-world data remains in development in many cases and will require additional investment. Determining the utility of different types of data can inform how much to invest in data generation and analysis.

\section{Patient Selection}

Identifying which patients are appropriate candidates for a treatment is essential for ensuring that resources are used wisely. Patient selection criteria should be thoughtfully designed with input from clinicians and relevant therapeutic guidelines. Participants recommended a rigorous criteria review process based on standards and best practices. Realworld evidence, FDA labeling, and compendia could also be used to refine patient selection criteria. They noted that consistency among plans would help prevent shifting of patients to plans with fewer requirements and would facilitate management of outcomes measures.
Avoiding inappropriate coverage denials was identified as an important goal. To minimize denials, providers should have a clear understanding of which patients are appropriate candidates and what information is required for coverage decisions. In the event of a denial, the reason should be clear, and someone with clinical expertise, such as a clinical pharmacist, should be available to explain the denial to the provider.

\section{Addressing Legal and Regulatory Challenges}

There are several potential creative strategies for managing high-investment medications, but current laws and regulations constrain the implementation of innovative payment models (Table 3). There is a need for the development of so-called safe harbors to allow greater flexibility in benefit designs and reduce uncertainty and potentially expensive compliance risk for those developing alternative payment models. Participants noted that some issues relating to contracting around the use of a drug outside the labeled indications are somewhat addressed in recent FDA guidance regarding preapproval information exchange, but these developments have not been codified into law. ${ }^{4}$

\section{Strategies for Moving Forward}

Participants generated several potential solutions to minimize challenges that high-investment medications pose for access and payment, including legal and regulatory strategies, realworld evidence generation, and those that could be addressed by managed care stakeholders or AMCP. While participants did not agree on all strategies proposed, there was agreement that opportunities to remove barriers should be explored.

\section{Legal and Regulatory Strategies}

Some participants focused on contracting barriers and limitations posed by Medicaid best price requirements and expressed a need to create a safe harbor to allow for experimentation with various models, such as value-based contracts. Such experimentation would allow stakeholders to assess the effect of various contract structures on overall costs and outcomes and determine whether these contracts are effective at managing costs. While some value-based contracts have already been implemented, removing Medicaid best price constraints would allow the development of a wider range of contracts.

Enhanced preapproval information exchange among stakeholders was identified as another avenue for improving management strategies. Manufacturer communications with payers about products in development allows payers to be better prepared to manage the products when they are approved. Participants discussed areas for which preapproval information would be helpful for payers during the development of coverage policies and programs. These areas included anticipated costs, patient populations, required ancillary services, and expected outcomes. 
TABLE 3 Laws and Regulations that May Affect Payment Models

- Antidiscrimation laws

- Antitrust laws

- Anti-Kickback Statute

- Average sales price reporting

- False Claims Act

- Health Insurance Portability and Accountability Act

- Laws and regulations regarding off-label promotion

- Medicaid best price

- Stark Law (prohibits self-referral)

- State laws and regulations, such as required reserves for plans and benefits mandates

Participants suggested that some payers could experiment with selected models with Medicaid payers, thereby avoiding challenges posed by Medicaid best price constraints. They also observed that self-funded employer plans might have greater flexibility than other plans but would not be exempt from Medicaid best price.

As one potential approach in the absence of broader safe harbors or clarification, some participants suggested the implementation of a process at the state or federal level to exempt or waive certain requirements (e.g., Medicaid best price guarantee and average sales price reporting). They recommended that AMCP convene a forum of stakeholders with the appropriate expertise to clarify the specific desired scope for such a process.

\section{Real-World Evidence Generation}

While some participants focused on contracting barriers and the limits due to Medicaid best price, other participants stressed the need for real-world evidence data generation with appropriate access and transparency of clinical and cost information. Access to such data is essential for establishing the value of a therapy, administering contracts that are contingent upon outcomes, assessing return on investment, and guiding adjustments to coverage and contracting strategies.

Shared documentation and transparency as a component of real-world evidence generation is also needed. Because performance outcomes are usually associated with metrics associated with medical benefits, pharmacy systems will need to be able to collect data from medical benefit systems, which has historically been a challenge in many plans.

\section{Managed Care Stakeholder Collaborations}

Collaboration on flexible benefit designs and new payment models for high-investment medications is key for managed care stakeholders to facilitate mutual understanding of various stakeholder needs to better understand each other's needs to support development of mutually agreeable solutions. For example, there is a potential for competing priorities and nonalignment between employers and third-party payers; ideally, these stakeholders will be able to agree on goals regarding appropriate level of coverage based on available resources.

\section{AMCP Roles and Opportunities}

Participants viewed AMCP as being well positioned to convene key resources and stakeholders to advance strategies for better managing high-investment medications and to serve as a clearinghouse to collect and disseminate the designs and results of alternative payment model experiments. Participants recommended that AMCP continue to serve as a key facilitator for stakeholder collaborations and as a conduit for communication and education about a range of factors, including legal and regulatory issues and benefit design.

The AMCP Foundation could support pilots for innovative contracting strategies and was proposed as a "safe space" to incubate new ideas and foster collaborations with other entities. They also suggested adapting AMCP's dossier system to create a centralized source of preapproval information and using the system to facilitate assessments of the value of highinvestment medications.

Participants recognized AMCP as an active advocate for strategies that promote solutions to challenges faced by managed care stakeholders. Participants acknowledged the value that $\mathrm{AMCP}$ provides in this space and suggested developing and maintaining partnerships with other organizations whose interests align in maintaining a sustainable and innovative health care system.

\section{Conclusions}

The approval of increasing numbers of high-investment medications is raising questions regarding the current payment system for pharmaceutical products. High-investment medications must be economically justified within sustainable pricing models to maintain the long-term viability of the insurance market.

A new paradigm that addresses concerns about how to pay for these medicines is needed to ensure that patients have access to these innovations. Several innovative models have been proposed, each with their own benefits, challenges, and potential roles in the payment landscape. Aspects of various models could potentially be combined with each other, as well as other models that were not specifically addressed at the forum.

While consensus was not reached by all forum participants, broadly, the implementation of innovative payment models will require that stakeholders address legal and regulatory challenges, implement strategies that improve transparency, support access to real-world evidence, and strengthen industry partnerships. 


\section{Forum Participants}

JANE BARLOW, MD, MPH, MBA, CEO, Jane Barlow \& Associates; CYNTHIA BENS, Senior Vice President, Public Policy, Personalized Medicine Coalition; TIM BRENT, MBA, Senior Director, Business Development, National Hemophilia Foundation; MICHAEL CIARAMETARO, MBA, Vice President of Research, National Pharmaceutical Council; COLLIN CONWAY, PharmD, Manager, Pharmacy Product Development \& Business Analysis, Kaiser Permanente Washington; JEREMY FREDELL, PharmD, BCPS, Director, Trend Solutions, Express Scripts; STEPHEN GEORGE, PharmD, MS, Senior Consultant, Milliman; MATTHEW HARMAN, PharmD, MPH, Director of Pharmacy, Employers Health Coalition; BARBARA HENRY, RPh, Lead Clinical Pharmacy Specialist, Harvard Pilgrim Health Plan; DOROTHY HOFFMAN, MPP, Vice President, UnitedHealth Group; SCOTT JAUCH, MS, Director, Oncology Access Strategy, AstraZeneca; PAUL JEFFREY, PharmD, Director of Pharmacy and Associate Professor, MassHealth/ University of Massachusetts Medical School; PAMELA KEITH, Director, Reimbursement, Access and Value Strategy, Celgene; LAURA KOONTZ, PhD, Personalized Medicine Staff, Food and Drug Administration; GENIA LONG, MPP, Senior Advisor, Analysis Group; SUNIL MAJETHIA, PharmD, Associate Director, Medical Sciences, Gilead Sciences; BILL MARTIN, Chief Commercial Officer, Accredo; SETH MARTIN, MD, MHS, FACC, FAHA, FASPC, Assistant Professor of Medicine, Johns Hopkins University School of Medicine; PAUL MINER, PharmD, National Medical Outcomes Scientific Liaison, Alnylam Pharmaceuticals; DONNA MONCUSO, MS, RN, Director, Payer \& Employer Outreach Programs, National Comprehensive Cancer Network (NCCN); JEFF MYERS, MBA, CEO, Medicaid Health Plans of America (MHPA); ANNETTE POWERS, PharmD, MBA, Executive Director, Celgene; SHIRLEY REITZ, PharmD, Clinical Pharmacist Client Manager, Cambia Health Solutions; WILLIAM ROGERS, MD, Chief Medical Officer, Applied Policy; BONNIE SHAUL, MBA, Director, Payer Strategy, AbbVie; KYLE SKIERMONT, PharmD, Chief Operating Officer, Fairview Pharmacy Services; JASON SPANGLER, MD, MPH, Executive Director, Amgen; ANA STOJANOVSKA, Vice President, Reimbursement \& Policy Insights, Xcenda; LOUIS THARP, Executive Director, Global Healthy Living Foundation; SUSAN TRIEU, PharmD, Director, Enterprise Specialty Clinical Solutions, MedImpact Healthcare Systems; ROBIN TURPIN, PhD, Value Evidence and Health Outcomes Scientific Lead, Takeda Pharmaceuticals, USA; JOE VANDIGO, MBA, PhD, Director, Policy $E$ Research, Pharmaceutical Research and Manufacturers of America (PhRMA); MELANIE WHITTINGTON, PhD, MS, Research Faculty, University of Colorado Anschutz Medical Campus.

AUTHOR CORRESPONDENCE: Tricia Lee Wilkins, PharmD, MS, PhD, Academy of Managed Care Pharmacy, 675 N. Washington St., Alexandria, VA 22314. Tel.: 703.684.264; E-mail: tlwilkins@amcp.org.

\section{DISCLOSURES}

The AMCP Partnership Forum and the development of the proceedings document were supported by Abbvie, Alnylam Pharmaceuticals, Amgen, AstraZeneca, Celgene, Gilead, the National Pharmaceutical Council, the Pharmaceutical Research and Manufacturers of America, Takeda, and Xcenda/AmerisourceBergen.

\section{ACKNOWLEDGMENTS}

The AMCP Partnership Forum "Designing Benefits and Payment Models for Innovative High-Investment Medications" was moderated by Susan Winckler, BSPh, JD, President, Leavitt Partners. These proceedings were written by Judy Crespi Lofton, MS (JCL Communications).

\section{REFERENCES}

1. Cutler D, Ciarametaro M, Long G, et al. Insurance switching and mismatch between the costs and benefits of new technologies. Am J Manag Care. 2017;23(12):750-57

2. Ciarametaro M, Long G, Johnson M, et al. Are payers ready to address the financial challenges associated with gene therapy? Health Affairs Blog. June 28, 2018. Available at: https://www.healthaffairs.org/do/10.1377/ hblog20180626.330036/full. Accessed January 14, 2019.

3. Slocomb T, Werner M, Haack T, Valluri S, Rader B. New payment and financing models for curative regenerative medicines. In Vivo. July/August 2017. Available at: https://www.hklaw.com/files/Uploads/Documents/ Articles/ARM_Curative_Regenerative_IV1707_LRS.pdf. Accessed January 14, 2019 .

4. Neumann PJ, Pope E. Cures Act, FDA draft guidance suggest flexibility on communication of real-world drug impacts, though questions remain. Health Affairs Blog. February 2, 2017. Available at: https://www.healthaffairs.org/do/10.1377/hblog20170202.058584/full. Accessed January 14, 2019 